\title{
UTILIZING GADGET BASED INTERNET APPROACH DURING THE PANDEMIC TO IMPROVE STUDENTS' BAHASA INDONESIA LEARNING OUTCOMES AT GRADE IV OF SD NEGERI 10 BAGAN PUNAK KECAMATAN BANGKO
}

\author{
Dahniar \\ SDN 010 Bagan Punak Kecamatan Bangko, Indonesia \\ khoirani12@gmail.com
}

\begin{abstract}
This study aimed to improve the students' learning outcomes at fourth grade of SDN 010 Bagan Punak, Kecamatan Bangko, through a gadget-based internet use approach. The subjects of this study consisted of 20 students. This research was classroom action research with the aim of improving the learning outcomes and learning activities. The results of the research found that the initial data on the average score of students' learning outcomes was only 60, meaning that it had not yet reached the completeness of the learning outcomes. Then, after learning to use the gadget-based internet with zoom media from cycle I to cycle II, students' learning outcomes increased from the beginning of learning when using gadget-based internet in learning Bahasa Indonesia and continued to increase in each cycle. This was evidence of the success of using internet in improving student learning outcomes. In the first cycle, there was a good increase in which the average value of students' learning outcomes as a whole was 74.6compared to the initial data which was only 60. The number of students with complete learning outcomes were 15 of the 20 students who took the learning outcomes test. it indicated around 75\% of the fourth grade students at SDN 010 Bagan Punak, Kecamatan Bangko Then, it was proceeded to the second cycle in which the average of students' learning outcomes also experienced a good increase. The students' learning outcomes in the second cycle was 81.8 meaning that has achieved good completeness. There were about 18 students from 20 students who took the learning outcomes test completed the test, meaning that around 90\% of fourth grade students at SDN 010 Bagan Punak, Kecamatan Bangko.
\end{abstract}

Keywords: internet, gadgets, Indonesian learning outcomes

\section{PENGGUNAAN INTERNET BERBASIS GADGET PADA MASA PANDEMI TERHADAP HASIL BELAJAR BAHASA INDONESIA SISWA KELAS IV SD NEGERI 10 BAGAN PUNAK KECAMATAN BANGKO}

\begin{abstract}
ABSTRAK
Penelitian ini bertujuan untuk meningkatkan hasil belajar bahasa Indonesia siswa kelas IV SDN 010 Bagan Punak Kecamatan Bangko melalui pendekatan penggunaan internet berbasis gadget. Subjek penelitian ini terdiri dari 20 orang siswa. Penelitian ini berupa penelitian tindakan kelas dengan tujuan memperbaiki serta meningkatkan hasil belajar dan aktivitas pembelajaran. Hasil penelitian yang dilakukan ditemukan data awal ratarata hasil belajar siswa hanya sebesar 60 hal tersebut tentu saja belum mencapai ketuntasan hasil belajar siswa. Kemudian setelah dilakukan pembelajaran menggunakan internet berbasis gadget dengan media zoom dari siklus I hingga siklus II hasil belajar siswa mengalami peningkatan yang baik dari awal pembelajaran pada saat penggunaan internet berbasis gadget pada pembelajaran Bahasa Indonesia dan terus meningkat pada setiap siklusnya, hal ini merupakan bukti keberhasilan penggunaan internet berbasis gadget dalam meningkatkan hasil belajar siswa. Hasil belajar siswa pada siklus I setelah perbaikan pembelajaran terjadi peningkatan yang baik dimana didapat nilai rata-rata hasil belajar siswa secara keseluruhan ialah berjumlah 74.6 terjadi peningkatan dibandingkan dengan data awal yang hanya sebesar 60 , jumlah siswa dengan hasil belajar yang tuntas yaitu sekitar 15 orang siswa dari 20 orang siswa yang mengikuti tes hasil belajar artinya sekitar 75\% siswa kelas IV SDN 010 Bagan Punak Kecamatan Bangko. Kemudian dilanjutkan ke siklus II rata-rata hasil belajar siswa juga mengalami peningkatan yang baik, hasil belajar siswa pada siklus II setelah perbaikan pembelajaran terjadi peningkatan yang baik dimana didapat nilai rata-rata hasil belajar siswa secara keseluruhan ialah berjumlah 81.8 tentu saja hal tersebut sudah mencapai ketuntasan yang baik yaitu sekitar 18 orang siswa yang tuntas dari 20 orang siswa yang mengikuti tes hasil belajar artinya sekitar 90\% siswa kelas IV SDN 010 Bagan Punak Kecamatan Bangko.
\end{abstract}

Kata Kunci: internet, gadget, hasil belajar bahasa Indonesia

\begin{tabular}{|c|c|c|}
\hline Submitted & Accepted & Published \\
\hline 03 Agustus 2021 & 08 September 2021 & 17 September 2021 \\
\hline
\end{tabular}

\begin{tabular}{|l|c|c|}
\hline Citation & $:$ & $\begin{array}{r}\text { Dahniar. (2021). Utilizing Gadget Based Internet Approach during the Pandemic to Improve Students' Bahasa Indonesia } \\
\text { Learning Outcomes at Grade IV of SD Negeri 10 Bagan Punak Kecamatan Bangko. Jurnal PAJAR (Pendidikan } \\
\text { dan Pengajaran), 5(5), 1514-1520. DOI : http://dx.doi.org/10.33578/pjr.v5i5.8551. }\end{array}$ \\
\hline
\end{tabular}




\section{PENDAHULUAN}

Pada masa kemajuan teknologi saat ini segala sesuatu yang dilakukan selalu melibatkan teknologi terutama smartphone atau gadget yang dapat memudahkan segala urusan kita sehingga membuat kita tidak terlepas dari yang namanya gadget tersebut. Tidak hanya mempermudah kegiatan kita sehari-hari, penggunaan gadget juga sangat diperlukan dalam dunia pendidikan saat ini terlebih lagi pada masa pandemi sekarang ini. Permasalahan di dalam dunia pendidikan saat ini menjadi prioritas utama yang harus diperbaiki, kualitas pendidikan pada saat ini tengah menghadapi hambatan dan tantangan akibat dampak dari Covid-19, akibatnya pemerintah harus bekerja sama dengan seluruh pihak untuk menekan laju penyebaran Covid-19 dengan mengeluarkan kebijakan sosial distancing atau sering kita sebut work from home (Cahyani, dkk, 2017).

Hal itu juga berdampak pada dunia pendidikan Indonesia sehingga anak-anak tidak bisa melakukan kegiatan pembelajaran disekolah melainkan sekolah dari rumah. Keadaan ini tentu saja memberikan dampak pada kualitas pembelajaran, siswa dan guru yang dulunya belajar secara tatap muka dan berinteraksi langsung dalam ruang kelas dan memiliki kebebasan dalam belajar sekarang harus berinteraksi dalam virtual yang terbatas. Guru dituntut memberikan pengajaran yang baik, menciptakan suasana yang kondusif dalam mendukung belajar secara daring dan secara kreatif dan inovatif menggunakan media belajar yang menarik dan mudah dipahami agar siswa tidak kesulitan dalam memahami materi dan tujuan pembelajaran dapat tercapai. Oleh karena itu guru dan siswa harus mengetahui teknologi saat ini tidak boleh gaptek agar dapat menjalankan tugas mengajarnya dengan baik dan dapat mengukuti kurikulum yang ada. Tidak dapat dipungkiri dengan adanya Covid-19 semua pembelajaran baik dari tingkat SD, SMP, SMA, dan perkuliahan menggunakan sistem pembelajaran daring. Disini berbagai alat elektronik dibutuhkan diantaranya laptop dan gadget. Media pembelajaran yang digunakan harus bersifat online seperti whatsapp, google classroom, zoom, google mate, E-Learing, dll. Pada saat ini penggunaan aplikasi zoom sudah umum digunakan dalam pembelajaran, penggunaan aplikasi zoom ini dapat di gunakan menggunakan komputer maupun gadget, Zoom dapat dikatergorikan sebagai media pembelajaran online yang dapat diartikan sebagai suatu jenis belajar mengajar yang memungkinkan tersampaikannya bahan ajar ke siswa dengan menggunakan media Internet. Media pembelajaran online sebagai sebuah alternatif pembelajaran yang berbasis elektronik memberikan banyak manfaat terutama terhadap proses pendidikan yang dilakukan dengan jarak jauh.

Secara estimologi, gadget berasal dari istilah perangkat elektronik kecil yang memiliki fungsi khusus. Gadget juga merupakan alat atau barang teknologi kecil yang memiliki fungsi khusus, tetapi sering diasosiasikan sebagai inovasi baru (Farida, 2017). Gadget juga memiliki fungsi utama sebagai alat komunikasi, juga dapat digunakan sebagai sarana bisnis, sumber informasi, penyimpanan berbagai macam data, sarana musik atau hiburan, jejaring sosial bahkan sebagai alat dokumentasi. Beberapa pemanfaatan gadget selain untuk komunikasi dan bermain, gadget dapat dimanfaatkan sebagai sarana belajar. Sejalan dengan pendapat Kurnia dan Ghifari, (2018) Gadget adalah perangkat elektronik mempunyai fungsi khusus, misalnya dapat digunakan sebagai perekam suara, memutar video, menampilkan foto, dan dapat dijadikan sebagai alat pengawas atau komunikasi. Gadget memiliki point lebih dari alat elektronik lainnya, yaitu kebaharuannya. Artinya, dari hari ke hari gadget selalu muncul dengan menyajikan teknologi baru yang mempermudah manusia dalam melakukan suatu hal. (Iswidharmajaya \& Derry, 2014) gadget adalah suatu istilah yang berasal dari bahasa Inggris untuk merujuk pada suatu peranti atau instrument yang memiliki tujuan dan fungsi praktis yang berguna umumnya diberikan terhadap sesuatu yang baru. Gadget memiliki kecanggihan lebih di bandingkan dengan teknologi lainnya. Dengan demikian dapat disimpulkan bahwa, gadget merupakan perangkat elektronik yang diciptakan dalam 
bentuk teknologi informasi dan memiliki fungsi yang spesifik sesuai dengan konteks pada era globalisasi dan memudahkan manusia dalam berkomunikasi.

Selain dari berbagai pengaruh positif atau mempermudah guru dan siswa dalam proses pembelajaran, gadget juga dapat berdampak tidak baik bagi anak jika penggunaan secara berlebihan dan digunakan kepada hal yang tidak baik, oleh karena itu disini peran orang tua sangat diperlukan dalam mengawasi serta membimbing anak dalam menggunakan teknologi yang canggih seperti saat ini agar anak tidak jatuh kepada hal-hal yang tidak baik.

Dengan adanya berbagai teknologi pada saat ini diharapkan dapat membantu kelangsungan proses pembelajaran dengan baik serta dapat meningkatkan hasil belajar bahasa Indonesia kelas IV SDN 010 Bgan Punak Kabupaten Rokan Hilir. Hasil belajar merupakan tolak ukur untuk menentukan keberhasilan peserta didik dalam penguasaan materi yang telah mereka pelajari. Hasil belajar akan diperoleh peserta didik ketika sudah melaksanakan proses belajar. Slameto (2010) menyatakan bahwa terdapat faktor-faktor yang mempengaruhi hasil belajar itu sendiri yaitu faktor eksternal dan faktor internal. Dimana faktor internal berupa minat, aktivitas, sikap dan lain sebagainya. Sedangkan faktor eksternal meliputi fasilitas, dukungan orang tua dan lain sebagainya. Hasil belajar adalah hasil yang dicapai individu setelah mengalami proses adaptasi dengan lingkungannya maupun pengalamannya (belajar) (Rosiyanti, 2015). Belajar adalah suatu proses usaha yang dilakukan oleh individu untuk memperoleh perubahan tingkah laku baru secara keseluruhan, sebagai hasil dari pengalaman individu itu sendiri dalam berinteraksi dengan lingkungannya (Nana Sudjana, 2004).

Melihat berbagai definisi hasil belajar menurut para ahli diatas dapat disimpulkan bahwa hasil belajar merupakan suatu hasil yang didapatkan suatu individu melalui proses belajar baik itu dari pengalaman maupun belajar formal yang dapat berupa perubahan tingkah laku maupun suatu prestasi dalambidang tertentu.

\section{METODE PENELITIAN}

Penelitian ini berupa penelitian tindakan kelas, Secara harfiah, penelitian tindakan kelas berasal dari bahasa Inggris yaitu Classroom Action Research artinya action research (penelitian dengan tindakan) yang dilakukan di kelas. Penelitian ini dilakukan untuk memecahkan suatu masalah yang ada dalam proses pembelajaran dan untuk meningkatkan hasil pembelajaran yang ada didalam kelas. Arikunto (2014) menyatakan penelitian tindakan kelas adalah kajian sistematik dari upaya perbaikan pelaksanaan praktek pendidikan oleh sekolompok guru dengan melakukan tindakan-tindakan dalam pembelajaran , berdasarkan refleksi mereka mengenai hasil tindakan-tindakan tersebut. Penelitian tindakan kelas adalah penelitian yang dilakukan oleh guru di dalam kelasnya sendiri melalui refleksi diri, dengan tujuan untuk memperbaiki kinerja sebagai guru, sehingga hasil belajar siswa menjadi meningkat (Wardani dan Wihardit, 2008).

Penelitian ini dilakukan pada Juli 2021 di SDN 010 Bagan Punak Kecamatan Bangko Kabupaten Rokan Hilir. Jumlah subjek dalam penelitian ini sebanyak 20 orang siswa kelas IV. Instrument dalam penelitian ini terdiri dari soal ulangan (tes hasil belajar) dan observasi. Tujuan penelitian ini adalah untuk melihat keefektifan penggunaan internet berbasis gadget terhadap hasil belajar siswa kelas IV SDN 010 Bagan Punak.

\section{Teknik Analisis Data}

Teknik analisis data observasi aktivitas guru dan siswa dalam penelitian ini menggunakan rumus sebagai berikut:

$$
p=\frac{\mathrm{f}}{\mathrm{n}} \times 100 \%
$$

(Anas Sudijono, 2004)

Keterangan:

$\mathrm{f}=$ Frekuensi yang sedang dicari persentasenya

$\mathrm{n}=$ Number of Cases (jumlah frekuensi/banyaknya individu)

$\mathrm{P}=$ Angka persentase

$100 \%=$ Bilangan Tetap 
Tabel 1. Klasifikasi Pengukuran Persentase Hasil Observasi Aktivitas Guru dan Siswa

\begin{tabular}{|c|c|c|}
\hline No & Klasifikasi & Persentase (\%) \\
\hline 1 & Baik & $67-100$ \\
\hline 2 & Cukup Baik & $34-66$ \\
\hline 3 & Kurang Baik & $0-33$ \\
\hline
\end{tabular}

(Arikunto, 2014).

Untuk analisis hasil belajar siswa melalui pemberian tes berupa ulangan harian menggunakan rumus sebagai berikut:

$$
p=\frac{\text { posrate }}{\text { baserate }} \times 100 \%
$$

(Zainal Aqib, 2009)

Keterangan:

$\mathrm{P}=$ persentase peningkatan.

Posrate = nilai sesudah diberikan tindakan .
Baserate = nilai sebelum tindakan

\section{HASIL DAN PEMBAHASAN}

\section{a. Observasi}

Analisis kegiatan pembelajaran berupa aktivitas guru saat mengajar dilakukan sebanyak 2 siklus, berdasarkan data awal ditemukan hasil observasi aktivitas guru hanya 55\% hal itu masih dikategorikan cukup baik. Berikut adalah tabel aktivitas guru setelah refleksi pembelajaran:

Tabel 2. Persentase aktivitas guru siklus I dan siklus II

\begin{tabular}{llll}
\hline Siklus & Pertemuan & Persentase & kategori \\
\hline I & I & $63 \%$ & Cukup baik \\
& II & $66 \%$ & Cukup baik \\
II & III & $86 \%$ & Baik \\
& IV & $94 \%$ & Baik \\
\hline
\end{tabular}

Dapat dilihat dari tabel diatas penelitian pada siklus I pertemuan pertama persentase aktivitas guru didapat sebanyak $63 \%$ pada kategori cukup baik, kemudian pada pertemuan kedua didapat persentase aktivitas guru sebesar $66 \%$ pada kategori cukup baik. Setelah pelaksanaan siklus I dilanjutkan ke siklus II aktivitas guru terjadi peningkatan pada pertemuan ketiga didapat persentase aktivitas guru sebesar $86 \%$ pada kategori baik, pada pertemuan keempat didapat persentase aktivitas guru sebesar $94 \%$ pada kategori baik.

Hasil observasi analisis aktivitas kegiatan siswa dalam pembelajaran sebelum dilakukan refleksi pembelajaran dan sesudah dilakukan refleksi pembelajaran dapat kita lihat pada tabel berikut:

Tabel 3. Persentase aktivitas siswa siklus I dan siklus II

\begin{tabular}{llll}
\hline Siklus & Pertemuan & Persentase & Kategori \\
\hline I & I & $58 \%$ & Cukup baik \\
& II & $64 \%$ & Cukup baik \\
II & III & $81 \%$ & Baik \\
& IV & $87 \%$ & Baik \\
\hline
\end{tabular}

Dapat dilihat dari tabel diatas persentase aktivitas siswa pada siklus I dan siklus II meningkat pada setiap pertemuannya. Pada siklus I pertemuan pertama didapat persentase $58 \%$ pada kategori cukup baik, pada pertemuan kedua didapat persentase sebesar $64 \%$ masih dengan kategori cukup baik. Pada siklus ke II peningkatan aktivitas siswa mengalami peningkatan dapat dilihat pada pertemuan ketiga didapat persentase sebesar $81 \%$ pada kategori baik, dan pada pertemuan keempat didapat persentase sebesar $87 \%$ pada kategori baik. 


\section{b. Hasil belajar}

Berikut adalah tabel analisis hasil belajar siswa kelas IV SDN 010 Bagan Punak Kecamatan Bangko:

Tabel 4. Hasil Belajar Siswa Siklus II

\begin{tabular}{|l|l|l|l|}
\hline NO. & NAMA & NILAI & KETERANGAN \\
\hline 1. & NA & 70 & T \\
\hline 2. & AM & 72 & T \\
\hline 3. & AL & 60 & TT \\
\hline 4. & NZ & 80 & T \\
\hline 5. & NAZ & 90 & T \\
\hline 6. & KY & 72 & T \\
\hline 7. & MS & 76 & T \\
\hline 8. & SY & 89 & T \\
\hline 9. & OL & 65 & TT \\
\hline 10. & AZ & 70 & T \\
\hline 11. & RS & 80 & T \\
\hline 12. & JU & 87 & T \\
\hline 13. & MF & 81 & T \\
\hline 14. & RK & 88 & T \\
\hline 15. & IB & 72 & T \\
\hline 16. & MH & 64 & TT \\
\hline 17. & BP & 73 & T \\
\hline 18. & ER & 60 & TT \\
\hline 19. & BL & 86 & T \\
\hline 20. & FR & 58 & TT \\
\hline JUMLAH NILAI & 1493 \\
\hline RATA-RATA & & 74,6 \\
\hline PERSENTASE KETUNTASAN & $75 \%$ \\
\hline
\end{tabular}

Dapat dilihat pada tabel diatas hasil belajar siswa pada siklus I setelah perbaikan pembelajaran terjadi peningkatan yang baik dimana didapat nilai rata-rata hasil belajar siswa secara keseluruhan ialah berjumlah 74.6 terjadi peningkatan dibandingkan dengan data awal yang hanya sebesar 60, jumlah siswa dengan hasil belajar yang tuntas yaitu sekitar 15 orang siswa dari 20 orang siswa yang mengikuti tes hasil belajar artinya sekitar $75 \%$ siswa kelas IV SDN 010 Bagan Punak Kecamatan Bangko. Kemudian dilanjutkan ke siklus II rata-rata hasil belajar siswa juga mengalami peningkatan yang baik.

Berikut adalah data hasil analisis hasil belajar siswa kelas IV SDN 010 Bagan Punak Kecamatan Bangko pada Siklus II:

Tabel 5. Hasil Belajar Siswa Siklus II

\begin{tabular}{|l|l|l|l|}
\hline NO. & NAMA & NILAI & KETERANGAN \\
\hline 1. & NA & 76 & T \\
\hline 2. & AM & 75 & T \\
\hline 3. & AL & 65 & TT \\
\hline 4. & NZ & 78 & T \\
\hline 5. & NAZ & 98 & T \\
\hline 6. & KY & 78 & T \\
\hline 7. & MS & 55 & TT \\
\hline 8. & SY & 89 & T \\
\hline
\end{tabular}




\begin{tabular}{|l|l|l|l|}
\hline 9. & OL & 85 & $\mathrm{~T}$ \\
\hline 10. & $\mathrm{AZ}$ & 77 & $\mathrm{~T}$ \\
\hline 11. & $\mathrm{RS}$ & 88 & $\mathrm{~T}$ \\
\hline 12. & $\mathrm{JU}$ & 90 & $\mathrm{~T}$ \\
\hline 13. & $\mathrm{MF}$ & 86 & $\mathrm{~T}$ \\
\hline 14. & $\mathrm{RK}$ & 98 & $\mathrm{~T}$ \\
\hline 15. & $\mathrm{IB}$ & 78 & $\mathrm{~T}$ \\
\hline 16. & $\mathrm{MH}$ & 90 & $\mathrm{~T}$ \\
\hline 17. & $\mathrm{BP}$ & 75 & $\mathrm{~T}$ \\
\hline 18. & $\mathrm{ER}$ & 84 & $\mathrm{~T}$ \\
\hline 19. & $\mathrm{BL}$ & 92 & $\mathrm{~T}$ \\
\hline 20. & FR & 80 & $\mathrm{~T}$ \\
\hline JUMLAH NILAI & & 1637 \\
\hline RATA-RATA & 81.8 \\
\hline \multicolumn{2}{l}{ PERSENTASE } & $90 \%$ \\
\hline
\end{tabular}

Dapat dilihat pada tabel diatas hasil belajar siswa pada siklus II setelah perbaikan pembelajaran terjadi peningkatan yang baik dimana didapat nilai rata-rata hasil belajar siswa secara keseluruhan ialah berjumlah 81,8 tentu saja hal tersebut sudah mencapai ketuntasan yang baik yaitu sekitar 18 orang siswa yang tuntas dari 20 orang siswa yang mengikuti tes hasil belajar artinya sekitar 90\% siswa kelas IV SDN 010 Bagan Punak Kecamatan Bangko.

\section{Pembahasan}

Penelitian ini berupa penelitian tindakan kelas yang dilakukan di kelas IV SDN 010 Bagan Punak Kecamatan Bangko, jumlah subjek dalam penelitian ini terdiri dari 20 orang siswa. Penelitian tindakan kelas adalah penelitian yang dilakukan oleh guru di dalam kelasnya sendiri melalui refleksi diri, dengan tujuan untuk memperbaiki kinerja sebagai guru, sehingga hasil belajar siswa menjadi meningkat (Wardani dan Wihardit, 2008). Tujuan penelitian ini adalah untuk melihat keefektifan penggunaan media zoom dalam proses pembelajaran dan hasil belajar siswa.

Berdasarkan dari hasil penelitian yang dilakukan ditemukan data awal rata-rata hasil belajar siswa hanya sebesar 60 hal tersebut tentu saja belum mencapai ketuntasan hasil belajar siswa. Kemudian setelah dilakukan pembelajaran menggunakan internet berbasis gadget dengan media zoom dari siklus I hingga siklus II hasil belajar siswa mengalami peningkatan yang baik dari awal pembelajaran pada saat penggunaan internet berbasis gadget pada pembelajaran Bahasa Indonesia dan terus meningkat pada setiap siklusnya, hal ini merupakan bukti keberhasilan penggunaan internet berbasis gadget dalam meningkatkan hasil belajar siswa. Hasil belajar siswa pada siklus I setelah perbaikan pembelajaran terjadi peningkatan yang baik dimana didapat nilai rata-rata hasil belajar siswa secara keseluruhan ialah berjumlah 74.6 terjadi peningkatan dibandingkan dengan data awal yang hanya sebesar 60, jumlah siswa dengan hasil belajar yang tuntas yaitu sekitar 15 orang siswa dari 20 orang siswa yang mengikuti tes hasil belajar artinya sekitar 75\% siswa kelas IV SDN 010 Bagan Punak Kecamatan Bangko. Kemudian dilanjutkan ke siklus II rata-rata hasil belajar siswa juga mengalami peningkatan yang baik, hasil belajar siswa pada siklus II setelah perbaikan pembelajaran terjadi peningkatan yang baik dimana didapat nilai rata-rata hasil belajar siswa secara keseluruhan ialah berjumlah 81,8 tentu saja hal tersebut sudah mencapai ketuntasan yang baik yaitu sekitar 18 orang siswa yang tuntas dari 20 orang siswa yang mengikuti tes hasil belajar artinya sekitar $90 \%$ siswa kelas IV SDN 010 Bagan Punak Kecamatan Bangko.

Hasil belajar siswa yang meningkat di setiap siklusnya dikarenakan selama kegiatan pembelajaran pada setiap siklus, guru terus meningkatkan pemanfaatan internet berbasis gadget untuk membantu siswa memperoleh informasi yang diperlukan tentang berbagai 
materi pelajaran. Menurut penelitian terdahulu yang dilakukan oleh Beauty Manumpil, dkk. (2015) telah membuktikan bahwa terdapat hubungan yang relevan antara penggunaan gadget dengan tingkat prestasi siswa. Penggunaan gadget dapat meningkatkan prestasi siswa dikarenakan siswa dapat dengan lebih mudah untuk memahami materi pembelajaran karena terdapat berbagai animasi-animasi yang di jadikan guru sebagai model pembelajaran yang baru sehingga membuat siswa lebih tertarik dan semangat belajar.

\section{SIMPULAN}

Hasil penelitian dan pembahasan menunjukkan bahwa penggunaan internet berbasis gadget dapat meningkatkan hasil aktivitas pembelajaran guru dan siswa serta hasil belajar siswa pada pembelajaran bahasa Indonesia di kelas IV SDN 010 Bagan Punak Kecamatan Bangko Kabupaten Rokan Hilir. Terbukti terjadinya peningkatan aktivitas belajar guru dan siswa serta hasil belajar siswa pada tiap siklus dan tiap pertemuan. Hasil belajar siswa pada siklus I setelah perbaikan pembelajaran terjadi peningkatan yang baik dimana didapat nilai rata-rata hasil belajar siswa secara keseluruhan ialah berjumlah 74.6 terjadi peningkatan dibandingkan dengan data awal yang hanya sebesar 60 , jumlah siswa dengan hasil belajar yang tuntas yaitu sekitar 15 orang siswa dari 20 orang siswa yang mengikuti tes hasil belajar artinya sekitar 75\% siswa kelas IV SDN 010 Bagan Punak Kecamatan Bangko. Kemudian dilanjutkan ke siklus II rata-rata hasil belajar siswa juga mengalami peningkatan yang baik, hasil belajar siswa pada siklus II setelah perbaikan pembelajaran terjadi peningkatan yang baik dimana didapat nilai rata-rata hasil belajar siswa secara keseluruhan ialah berjumlah 81,8 tentu saja hal tersebut sudah mencapai ketuntasan yang baik yaitu sekitar 18 orang siswa yang tuntas dari 20 orang siswa yang mengikuti tes hasil belajar artinya sekitar 90\% siswa kelas IV SDN 010 Bagan Punak Kecamatan Bangko.

\section{DAFTAR PUSTAKA}

Anas. S. (2004). Pengantar Statistik Pendidikan. Jakarta: Raja Grafindo

Aqib. Z. (2009). PenelitianTindakan Kelas. Bandung: Yrama Widya.

Arikunto. S . (2014). Penelitian Tindakan Kelas. Jakarta: Rineka Cipta.

Cahyani. A. (2017). Motivasi Belajar Siswa SMA Pada Pembelajaran Daring Di Masa Pandemi Covid-19. 3(01), 123-40

Farida. (2017). Penggunaan Gadget Terhadap Hasil Belajar Mata Pelajaran IPS Siswa Kelas VII SMP Negeri 1 Kembangbahu Lamongan. Skripsi tidak diterbitkan Malang : PPs Universitas Islam Negeri Maulana Malik Ibrahim.

Ghifary dan Kurnia. (2015). Intensitas Penggunaan Smartphone Terhadap Perilaku Komunikasi. Jurnal Sosioteknologi, (Online). 14(3), 12-20.

Iswidharmajaya \& Derry. (2014). Bila Si Kecil Bermain Gadget: Panduan Bagi Orang Tua Agar Memahami Faktor-Faktor Penyebab Anak Kecanduan Gadget. Jakarta: EGC.

Manumpil, dkk. (2015). Hubungan Penggunaan Gadget dengan Tingkat Prestasi Siswa di SMA Negeri 9 Manado. Jurnal Keperawatan, (Online). 3(2).

Sudjana, N. (2004). Penilaian Hasil Belajar Mengajar. Bandung: Remaja Rosdakarya

Rosiyanti, H., dan Wijayanti, E. (2015). Implementasi Model Pembelajaran Treffinger Terhadap Hasil Belajar Matematika dan Sikap Siswa. Jurnal Fibonacci: Pendidikan Matematika dan Matematika. 1 (2), 37-44

Slameto. (2010). Belajar dan Faktor-Faktor yang Mempengaruhinya. Jakarta : Rineka Cipta.

Wardani \& Wihardit. (2008). Penelitian Tindakan Kelas. Jakarta: Universitas Terbuka. 